\title{
Research on the Scheduling of Legal Operating Vehicles based on NFC
}

\author{
Jiyan Lin, Peini Shang, Fei Yang and Yongheng Zhang \\ School of Information Technology, Yulin University, Yulin \\ linjiyan1018@163.com
}

\begin{abstract}
In the study of reasons that cause the flush illegal operating vehicles, we found out that the insufficient legal operating vehicles were the main cause. In order to efficiently solve the illegal operating, the paper brings out the research of scheduling algorithm about the legal operating vehicles based on NFC. The research uses the NFC technology to realize the intelligent and fast identification and the scheduling algorithm to realize the problem of insufficient legal operating vehicles. The scheduling can be divided into two stages--the multi-level queues high response ratio first scheduling and the multi-level queues earliest available time first scheduling. The algorithm can choose the user whose response ratio is the highest from the users'scheduling list and allocate the user who has the highest ratio to the legal operating vehicle who has the earliest available time that in the same area. Experiment indicates that the scheduling success ratio, throughput, average waiting time of the scheduling algorithm are superior to random travel of the drivers and can efficiently resolve the insufficient of legal operating vehicles.
\end{abstract}

Keywords: intelligent transportation; scheduling of legal operating vehicles'; two stages' scheduling algorithm; response ratio

\section{Introduction}

Illegal operating vehicles which we can call the unlicensed taxis exist in various places throughout the country and rampant despite repeated prohibitions in recent years. The illegal operating vehicles increase the law enforcement difficulty of the management of urban traffic and the public security, squeeze the legal operating vehicles' living space and bring the hidden trouble to the public traffic safety and the passenger rights. The illegal operating vehicles become a stubborn ill that perplex the fast growing of the modern cities and seriously damage the image of the city ${ }^{[1]}$.

The reason that causes the increase of illegal operating vehicles within a short time can be summarized as three. First, the number of the legal operating vehicles is too few. Second, the relevant regulatory authorities' supervise ineffectively in the early of the early inundation of the illegal operating vehicles. The third, the service of the legal operating vehicles is nonstandard which can reflect in the random carpool, refusal to take passengers and price increase. Because the ineffective management performance of the illegal operating vehicles using the punishment methods such as supervision of the traffic passenger transportation management, penalty, temporary detainment and confiscation, the measures that strengthening the input of the technology and solving the problems that the insufficient supply of the legal operating vehicles become the important tools to blow the illegal operating vehicles ${ }^{[2]}$. Aiming at the research status of the present and the rapid development of the intelligent traffic system of China and the widespread use of the NFC technology, the paper brings out the research of the scheduling algorithm of the legal operating vehicles. The research uses the modern 
information technology to provide the telephone and network call service, which can let the taxi service more diverse, and let the percent of finding taxi bigger and facilitate the citizens' activities ${ }^{[3]}$.

\section{Design of the Legal Operating Vehicles' Scheduling System}

The legal operating vehicles' scheduling system based on NFC mainly needs the traffic passenger transportation monitoring module, the passengers' telephones modules and the taxi's terminal module. The legal operating vehicles are equipped with the NFC tags which are granted by the legal operating vehicles enterprises. The NFC tags can identify the operating vehicles uniquely. The tags are pasted on the front glass of the vehicles. The algorithm also needs the scheduling module that can solve the insufficient of the legal operating vehicles' quantity. The passengers are equipped the telephones that own the NFC function. The traffic passengers' transportation monitoring module is equipped with the web server and the database server which can be used to manage the information of the passengers and the vehicles, and the scheduling module which can be used to schedule the legal operating vehicles based on the scheduling algorithm. The system overall structure is shown in Figure 1.

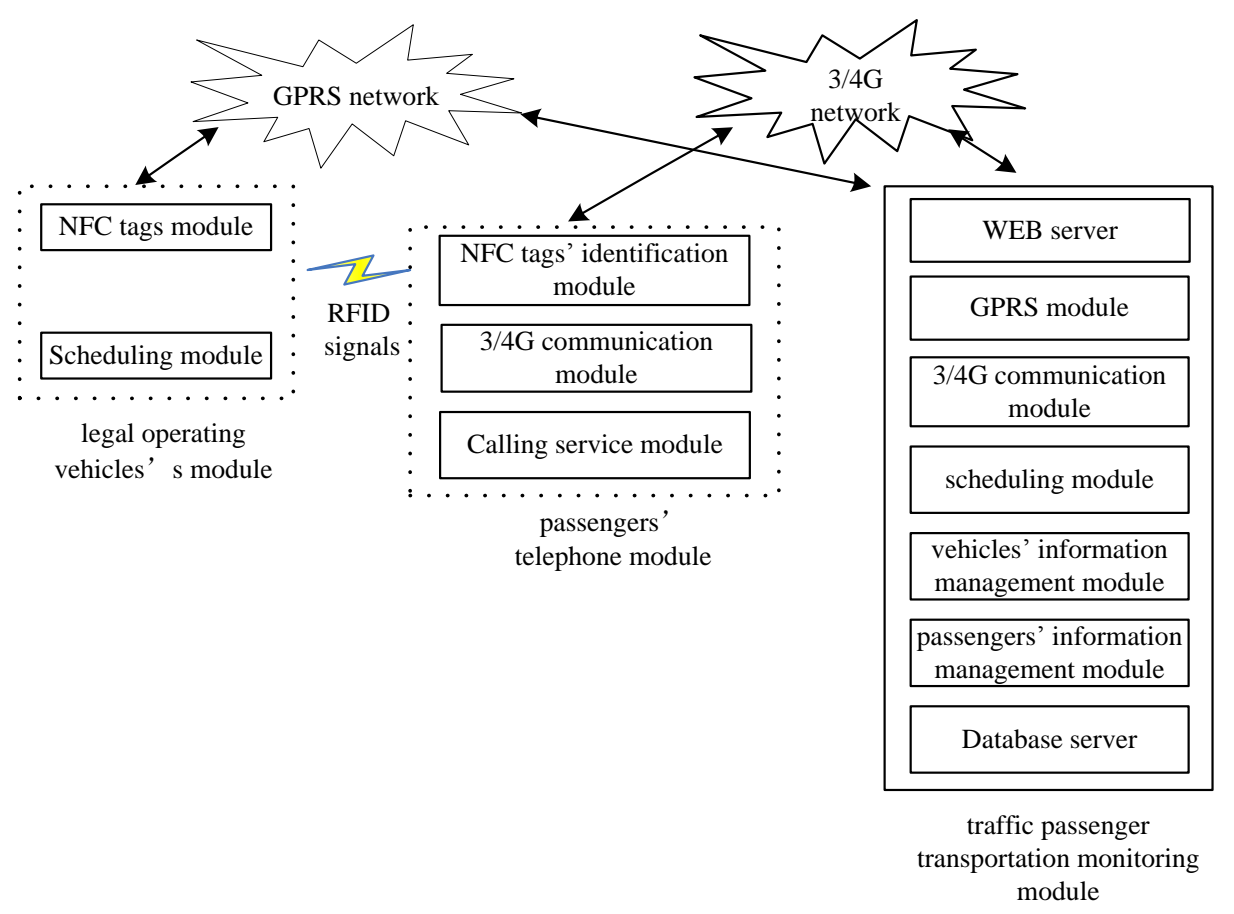

Figure 1. Legal Operating Vehicles' Scheduling System based on NFC

The scheduling system of the legal operating vehicles based on NFC can realize the following functions.

The NFC technology can realize the intelligent and fast identification of the operating vehicles. The system can solve the users' difficulty in finding whether the vehicles are the assigned operating vehicles or the legal operating vehicles. The users' telephones will be equipped with the NFC function. Before the passengers take on the vehicles, they firstly let their telephones close to the front glass of the front door. If the identification result shows "match", then it can prove that the vehicle is the legal operating vehicles that the system assigned to the passengers. If the identification result shows "no match", In this case, the passengers can choose to deny taking the vehicles. If the passengers choose to take the vehicles, he should press the "accept" button on the 
telephone and the passengers can read the information of the vehicles and evaluate the vehicles' service after they get off. If the legal operating vehicles' drivers detour on purpose or the service attitudes are harsh, the passengers also can complain the drivers. And the complaint information can be transferred to the monitoring center through the telephone network. If the passengers don't want to choose the vehicles because of the poor evaluation of the drivers, then the passengers should press the "deny" button. If the identification result shows "illegal", it indicates that the vehicle is not the legal vehicle, and the passengers can choose to report the vehicle's information through the phone.

The system can efficiently solve the insufficient quantity of the legal operating vehicles. The users can register in the monitoring system to call for taxi service. When the users open the GPS on the telephones, the traffic passengers' transportation management center can schedule the appropriate legal vehicles to the user. The legal operating vehicles that the management center provides to the users are decided by the scheduling algorithm. The main factors of the algorithm are the users' location , the destination of the users, the deadline of the calling service, the priority of the users, the location of the legal operating vehicles and the information whether the legal operating vehicles would accept the scheduling. The aim of the scheduling system is to satisfy the citizens' activities in maximum.

The work flow of the system can be shown in Figure 2.

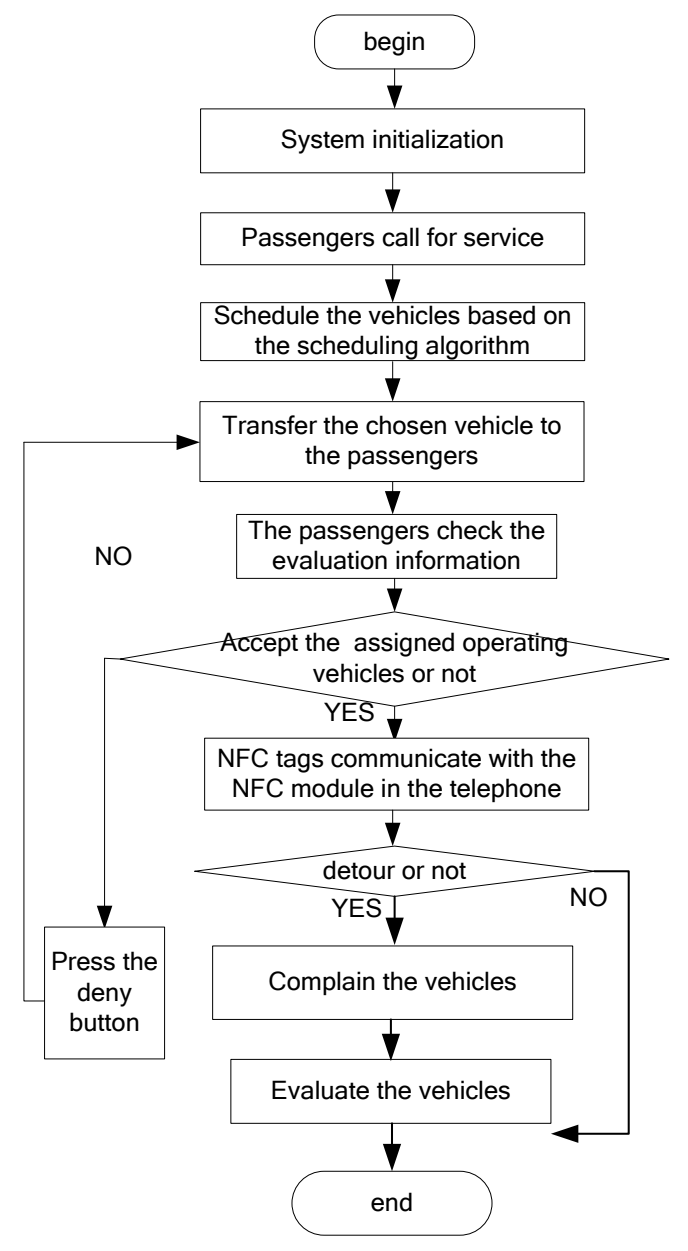

Figure 2. Work Flow Diagram of the Scheduling System 


\section{Design of the Legal Operating Vehicles' Scheduling System's Model}

The environmental model of the legal operating vehicles' scheduling system includes the calling taxi service's user model, the legal operating vehicles' model, the scheduling models and the restraint model. The model design as follows.

\section{$\mathrm{LOVSM}=(\mathrm{CM}, \mathrm{VM}, \mathrm{SM}, \mathrm{RM})$}

In the model, CM represents the calling taxi service's user model. VM represents the legal operating vehicles' model. SM represents the scheduling model and RM represents the restraint model.

\subsection{User Model of Calling Taxi Service}

The users that calling taxi service in a city are generally made up of different area which can be represented with directed acyclic graph (DAG). The DAG can be described with two-tuples, $(\mathrm{C}, \mathrm{E})$, in which the $\mathrm{C}$ represents the users that calling taxi service. $\mathrm{C}=\{\mathrm{c} 1, \mathrm{c} 2, \cdots \mathrm{ci}, \mathrm{cj}, \cdots \mathrm{cn}\}$ is the set of the users that calling taxi service. Every node represents a user that calling taxi service. The ci represents the ith user. The letter $\mathrm{n}$ represents the number of the users. $\mathrm{E}=\{\mathrm{e} 12, \mathrm{e} 13, \cdots \mathrm{eij}, \cdots\}$ is the set of the directed edges between the users. Every edge represents the "completed deadline" relation within the users that calling taxi service. Every user that calling taxi service is made up of eight attributes, which can be described as the calling taxi service's users' name(name), telephone(tel), the origin of taking a taxi(or), destination(dest), completed deadline(dl), estimated service time(est), starting service time(st), completed service time(cst). For the simulation experiment, the paper assumes that the users that calling taxi service is made up of two areas and the number of the users is 15 . The user model of calling taxi service can be built as Figure 3 and the concrete values of the eight attributes are described in the table 1 .

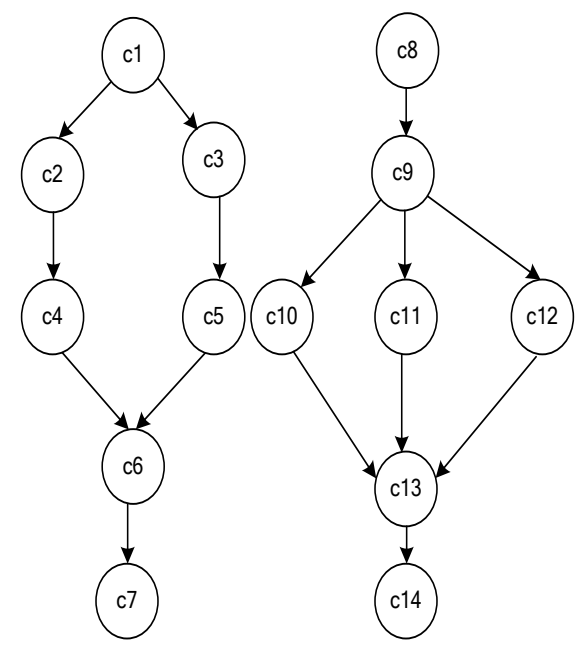

Figure 3. Taxi Service Users' DAG Diagram 
Table 1. Attributes of Calling Service

\begin{tabular}{|c|c|c|c|c|c|c|c|c|}
\hline users & name & tel & $\begin{array}{c}\text { or(GPS } \\
\text { coordinates) }\end{array}$ & $\begin{array}{c}\text { dest(GPS } \\
\text { coordinates) }\end{array}$ & $\begin{array}{l}\mathrm{dl} \text { (specific } \\
\text { moment) }\end{array}$ & $\begin{array}{c}\text { Est } \\
\text { (minutes) }\end{array}$ & $\begin{array}{l}\text { st(specific } \\
\text { momentg) }\end{array}$ & $\begin{array}{c}\text { cst(specific } \\
\text { moment) }\end{array}$ \\
\hline $\mathrm{c} 1$ & $\mathrm{u} 1$ & $\begin{array}{c}13697 \\
78546 \\
3\end{array}$ & $\begin{array}{l}\text { Chang Ning } \\
\text { community } \\
(109.738748,3 \\
8.289758) \\
\end{array}$ & $\begin{array}{l}\text { municipal } \\
\text { government } \\
(109.741224,38 . \\
290915) \\
\end{array}$ & $6: 50$ & 30 & $6: 00$ & $6: 40$ \\
\hline c2 & u2 & $\begin{array}{c}13377 \\
79546 \\
1\end{array}$ & $\begin{array}{l}\text { Ji Jian Wei } \\
\text { community } \\
(109.724695,3 \\
8.292258) \\
\end{array}$ & $\begin{array}{l}\text { Wen Hua } \\
\text { primary school } \\
(109.735554,38 . \\
292258) \\
\end{array}$ & $10: 50$ & 60 & 10:00 & $10: 52$ \\
\hline c3 & u3 & $\begin{array}{c}13595 \\
68546 \\
0\end{array}$ & $\begin{array}{l}\text { Rong Da hotel } \\
(109.73605,38 . \\
295313)\end{array}$ & $\begin{array}{l}\text { Sunshine Home } \\
(109.743603,38 . \\
298769)\end{array}$ & $12: 10$ & 50 & $11: 30$ & $12: 20$ \\
\hline c4 & $\mathrm{u} 4$ & $\begin{array}{c}13897 \\
88546 \\
5\end{array}$ & $\begin{array}{l}\text { Guan Di } \\
\text { temple } \\
(109.714457,3 \\
8.304537)\end{array}$ & $\begin{array}{l}\text { Cong Wen } \\
\text { community } \\
(109.724785,38 \text {. } \\
295182)\end{array}$ & $13: 50$ & 40 & $13: 00$ & $13: 45$ \\
\hline c5 & u5 & $\begin{array}{c}13995 \\
48546 \\
2\end{array}$ & $\begin{array}{l}\text { Guang Ji } \\
\text { mansion } \\
(109.753211,3 \\
8.300741)\end{array}$ & $\begin{array}{l}\text { Hai Long } \\
\text { Community } \\
(109.75361,38.3 \\
05376)\end{array}$ & $16: 50$ & 35 & $16: 00$ & $16: 30$ \\
\hline c6 & u6 & $\begin{array}{c}13693 \\
38546 \\
6\end{array}$ & $\begin{array}{l}\text { Yu Lin theater } \\
(109.759648,3 \\
8.295195)\end{array}$ & $\begin{array}{l}\text { Xi Sha hospital } \\
(109.743412,38 . \\
291922)\end{array}$ & 18:00 & 90 & $17: 00$ & $18: 15$ \\
\hline c7 & u7 & $\begin{array}{c}13592 \\
78546 \\
7\end{array}$ & $\begin{array}{l}\text { Experimental } \\
\text { primary } \\
\text { school(109.73 } \\
8514,38.28967 \\
7)\end{array}$ & $\begin{array}{l}\text { Environmental } \\
\text { protection } \\
\text { building } \\
(109.747058,38 . \\
298509)\end{array}$ & $23: 20$ & 15 & $22: 50$ & $23: 10$ \\
\hline c8 & u8 & $\begin{array}{c}13798 \\
98546 \\
8\end{array}$ & $\begin{array}{l}\text { Tenth middle } \\
\text { school } \\
(109.76223,38 . \\
298677)\end{array}$ & $\begin{array}{l}\text { Chang Qing } \\
\text { community } \\
(109.738488,38 . \\
290496)\end{array}$ & $6: 50$ & 30 & 6:00 & $6: 45$ \\
\hline c9 & u9 & $\begin{array}{c}13890 \\
18549 \\
0\end{array}$ & $\begin{array}{l}\text { Third } \\
\text { kindergarten } \\
(109.783477,3 \\
8.306879)\end{array}$ & $\begin{array}{l}\text { Wang Hu } \\
\text { community } \\
(109.783477,38 . \\
306879)\end{array}$ & $9: 30$ & 40 & 9:00 & 9:43 \\
\hline c10 & u10 & $\begin{array}{c}13123 \\
48543 \\
3\end{array}$ & $\begin{array}{l}\text { Third high } \\
\text { school(109.67 } \\
1726,38.30270 \\
7)\end{array}$ & $\begin{array}{l}\text { Xue Liang } \\
(109.704943,38 . \\
284834)\end{array}$ & $12: 00$ & 60 & 11:00 & $12: 03$ \\
\hline c11 & u11 & $\begin{array}{c}15645 \\
79545 \\
4\end{array}$ & $\begin{array}{l}\text { Century square } \\
(109.757828,3 \\
8.297342)\end{array}$ & $\begin{array}{l}\text { Kai Xin } \\
(109.757695,38 . \\
288573)\end{array}$ & $13: 50$ & 50 & $13: 00$ & 14:06 \\
\hline c12 & u12 & $\begin{array}{c}13697 \\
78546 \\
8\end{array}$ & $\begin{array}{l}\text { Bus station } \\
(109.763577,3 \\
8.2882370)\end{array}$ & $\begin{array}{l}\text { Experimental } \\
\text { primary } \\
\text { school(109.7385 } \\
04,38.289685) \\
\end{array}$ & $16: 50$ & 70 & $16: 00$ & $16: 47$ \\
\hline c13 & u13 & $\begin{array}{c}13500 \\
58546 \\
2\end{array}$ & $\begin{array}{l}\text { Yong Le } \\
\text { community } \\
(109.758861,3 \\
8.285887) \\
\end{array}$ & $\begin{array}{l}\text { Bei Fang } \\
\text { hospital } \\
(109.76107,38.2 \\
92411) \\
\end{array}$ & 18:00 & 50 & $17: 00$ & 18:02 \\
\hline c14 & u14 & $\begin{array}{c}13007 \\
89547 \\
6\end{array}$ & $\begin{array}{l}\text { Xing Yuan } \\
\text { library } \\
(109.75926,38 . \\
296544)\end{array}$ & $\begin{array}{l}\text { Chang Le } \\
\text { shopping mall } \\
(109.744221,38 . \\
290062)\end{array}$ & $22: 50$ & 60 & $22: 00$ & $22: 45$ \\
\hline
\end{tabular}




\subsection{Model of the Legal Operating Vehicles}

The capacity of carrying passengers, the quantity of carrying passengers and the working time of the legal operating vehicles in a city are not complete consistency. The service time that the same user takes different vehicles is not the very same. The model of the legal operating vehicles of a city can be represented with undirected graph. The graph describes with two-tuples(T,D) in which $\mathrm{T}$ represents the legal operating vehicles and $\mathrm{T}=\{\mathrm{t} 1, \mathrm{t} 2, \ldots \mathrm{t}, \mathrm{tj}, \ldots \mathrm{tn}\}$ represents the set of the legal operating vehicles. Every node represents a legal operating vehicle and ti represents the ith operating vehicle. The letter $\mathrm{n}$ represents the number of the users. $\mathrm{D}=\{\mathrm{d} 12, \mathrm{~d} 13, \ldots \mathrm{dij}, \ldots\}$ represents the set of the edges within the legal operating vehicles. Every edge between the legal operating vehicles represents the distance relation. Each legal operating vehicle is composed of driver name of legal operating vehicles(name), telephone(tel), location(loc), schedulability(sch), the earliest available time(et), the estimated time(est), the real service time(rst). The model of the legal operating vehicles is built as Figure 4 and the concrete values of the seven attributes are described in the table 2.

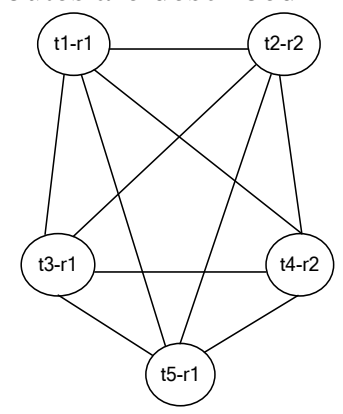

Figure 4. Model of Legal Operating Vehicle

Table 2. Attributes of Legal Operating Vehicle

\begin{tabular}{|c|c|c|c|c|c|c|c|}
\hline vehicles & name & tel & Loc(GPS coordinates) & sch & $\begin{array}{c}\text { et(specific } \\
\text { moment) }\end{array}$ & est(minutes) & rst(minutes) \\
\hline t1 & tu1 & $\begin{array}{c}130900 \\
85463\end{array}$ & $\begin{array}{c}\text { Bell tower } \\
(109.761842,38.296229)\end{array}$ & yes & $6: 00$ & 30 & 35 \\
\hline t2 & tu2 & $\begin{array}{c}132578 \\
59546\end{array}$ & $\begin{array}{c}\text { Second hospital } \\
(109.742083,38.283562)\end{array}$ & no & $8: 30$ & 35 & 40 \\
\hline t3 & tu3 & $\begin{array}{c}187956 \\
85460\end{array}$ & $\begin{array}{c}\text { Post office community } \\
(109.744532,38.284884)\end{array}$ & no & $12: 10$ & 72 & 63 \\
\hline t4 & tu4 & $\begin{array}{c}138978 \\
85426\end{array}$ & $\begin{array}{c}\text { Wu Liang temple } \\
(109.764601,38.306364)\end{array}$ & yes & $13: 50$ & 60 & 70 \\
\hline t5 & tu5 & $\begin{array}{c}136954 \\
85001\end{array}$ & $\begin{array}{c}\text { Agricultural bank } \\
(109.763456,38.289132)\end{array}$ & no & $18: 10$ & 83 & 70 \\
\hline
\end{tabular}

\subsection{Scheduling Model}

Concurrency exists when there is a lot of users that calling taxi service. So, the legal operating vehicles' scheduling system belongs to the real time concurrent system and its scheduling target is high scheduling success rate, high utilization rate, high throughput, short average turnaround time, short response time, deadline guarantee, nice fault tolerance and scalability. Therefore, in order to make all of the concurrent users get success scheduling and improve the concurrent ability, this research divides the users into areas. Meantime, the schedule is divided into two stages, the first stage uses the multi-level queues high response ratio first scheduling algorithm and the second stage uses multi-level queues earliest available time first scheduling algorithm. The first scheduling stage's target is users selecting which means that computes the users' 
response ratio in an area and ranks them and then selects the user that has the highest response ratio. The second scheduling stage's target is legal operating vehicles selecting which means that schedules the user that selected in the first stage to the most appropriate legal operating vehicle. The goal of the scheduling is making all of the users get the shortest finishing time. The scheduling model is shown in the Figure 5.

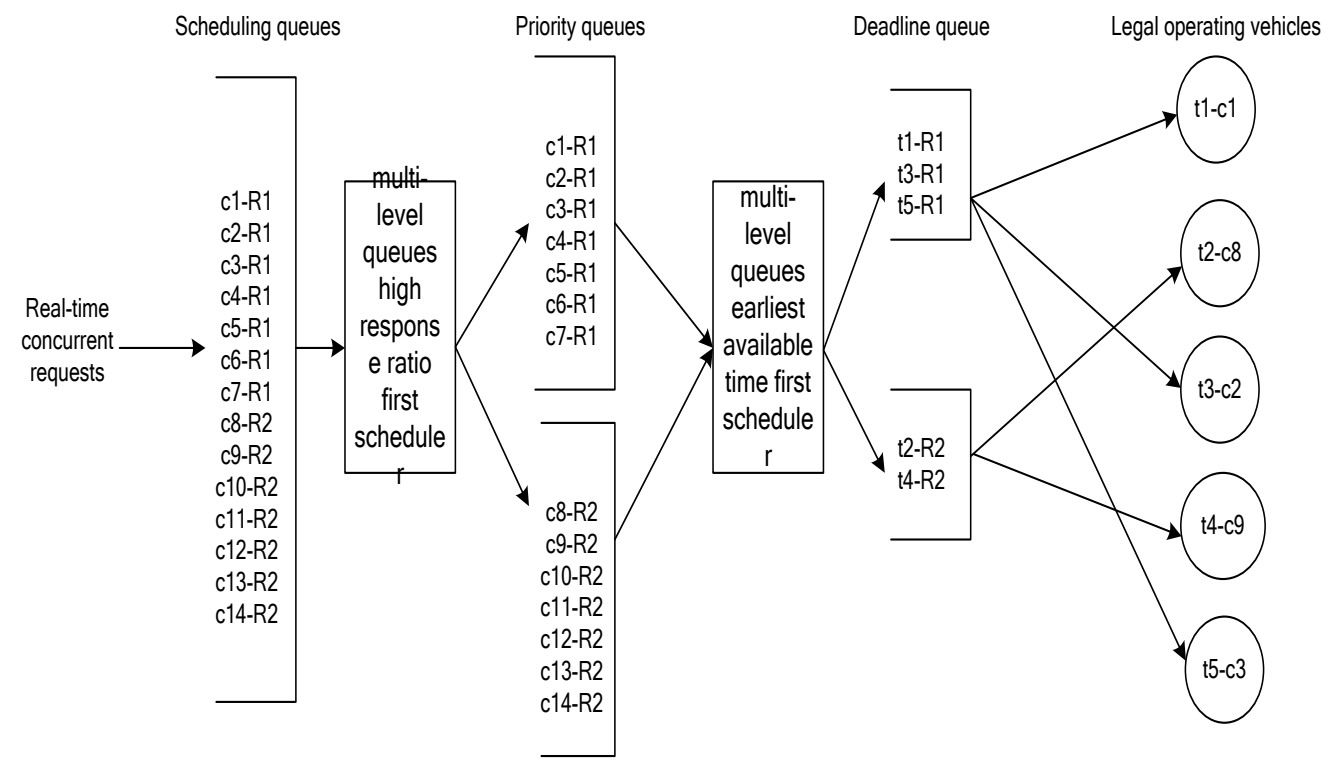

Figure 5. Scheduling Model Diagram

\subsection{Restraint Model}

In order to make the system's model close to the real environment, the paper defines some restraint condition.

Every request of the users that calling taxi service belongs to the real time task, therefore, it should be accomplished before the completed deadline as far as possible

A legal operating vehicle can only take one passenger at a given time and a passenger can only be serviced by one legal operating vehicle.

Once the user is allotted to some legal operating vehicle, the user cannot be preemptive.

The speed and the road congestion of each legal operating vehicle are not completely the same, therefore, the same user's service time is not completely when they takes different operating vehicles ${ }^{[5]}$.

\section{Design of the Legal Operating Vehicles' Scheduling Algorithm}

The algorithm the paper designed can be divided into two stages. The first stage is called the multi-level queues high response ratio first scheduling and the second stage is called the multi-level queues earliest available time first scheduling. The basic step of the algorithm can be described as follows.

Calculate the response ratio of the users that calling taxi service in each regions. The calculating is based on the certain scheduling policy.

Put the users that calling taxi service into the scheduling lists from high to low according to the response ratio.

Choose the user who has the highest response ratio form the users that calling taxi service and allotted him to the legal operating vehicle that has the earliest available time in the same area. Then deletes the user from the scheduling list. Repeat the process until 
the scheduling list is empty. The analysis and the design of the two stages of the algorithm will be described in 4.1 and 4.2.

\subsection{Multi-level Queues High Response Ratio First Scheduling Algorithm}

In order to make the number of the concurrent users as more as possible to get a timely response and successful scheduling, the legal operating vehicles' scheduling system should firstly consider the completed deadline. The earlier the completed deadline is, the sooner the user will be scheduled which can get the higher scheduling success ratio for the system. Secondly, the lesser time the user requests, the higher priority the user will get which can get the lesser average waiting time and improve the throughput for the system. Besides, the longer the user waits, the higher priority the user will get at the circumstance that the completed deadline and the requested service time are close which can avoid the circumstance that the users who request long service time will not be serviced for an infinite long time ${ }^{[6]}$. Therefore, the users' response ratio in each area is mainly decided by three factors, the completed deadline, the waiting time and the estimated service time. The computational formula is designed as formula 1.

$$
r r c=\frac{w t+e s t}{e s t+(d l-n t)}
$$

In the formula, the rrc represents the users' response ratio. The wt represents the waiting time, the unit is min. The est represents the estimated service time, the unit is min. The dl represents the completed deadline, the unit is min and the nt represents the current time, the unit is min.

The users are divided into multi-level queues according to the areas. The users in each queue are scheduled by the high response ratio first algorithm. In the process of building the users' multi-level high response ratio first queue, the first task is traversing the DAG diagram of the users that calling taxi service, and then calculates the every user's response ratio. After that, the users should be ranked based on the response ratio in descending order. In the ranking process, if the same response ratio is existed, the users should be ranked according to the completed deadline in descending order. At last, the scheduling queues of the users that calling taxi service will be obtained according to the twice ranker results. The basic step of the algorithm described as follows.

1) Firstly, setting multiple area queues for the users that calling taxi service according to the areas. The multiple area queues can realize the concurrent scheduling.

2) Firstly, calculates each user node's response ratio according to formula (1). And then ranks the users according to the response ratio in descent orders and initializes the users' scheduling queues.

3) If the same response ratios are existed, the users can be ranked according to the deadline in descent orders, and then updates the scheduling queues.

4) Check the user's area parameter when there is new user and then calculate his response ratio and insert the new user to the relevant position in the corresponding area queues. At last, update the scheduling queues.

5) while(if there are users that are not allocated in the scheduling queues) \{

Update the number of the available legal operating vehicles, the earliest available time, the number of the users that calling taxi service in this area;

if(the number of the available legal operating vehicles-t.num>0)

\{

Choose the node whose response ratio is the largest in the queue of the users that calling taxi service, that is the first user node ci;

Schedule the earliest available time scheduler;;

Delete the user from the scheduling list;

\}

else if(there are not the unallocated users in other areas and the number of the 
available legal operating vehicles $>0$ )

\{

Choose the user whose response ratio is the largest in the queue of the users that calling taxi service, that is the first user node ci;

Schedule the earliest available time scheduler;

Delete the user from the scheduling list;

\}

else blocked waiting;

\}

\subsection{Multi-level Queues Earliest Available Time First Scheduling Algorithm}

The task of this stage is choosing out the user who has the largest response ratio from the scheduling lists of the users that calling taxi service. Allocate the chosen user to the legal operating vehicle who has the earliest available time and in the same area with the user. The algorithm requests that a real-time queue of legal operating vehicle in the located area exists forever and in the queue, the legal operating vehicles are ranked from early to late by the available time. The legal operating vehicle that has the earliest available time is ranked in the most front of the scheduling queue. The basic step of the algorithm is described as follows.

1) Set up multiple area queues according to the areas for the legal operating vehicles. The multiple area queues can realize the concurrent scheduling;

2) Initialize the scheduling queue of the legal operating vehicles. Inside the queue, the legal operating vehicles are queued by the earliest available time. The sooner the available time is, the more priority the legal operating vehicle has. If the same earliest available time of the legal operating vehicles exists, the random choice can be carried through;

3) If there is new legal operating vehicles can be used, check the area parameter and insert it into the relevant position in the corresponding area queues. At last, update the scheduling queues;

4) if(the number of the users that calling taxi service-c.num>0)

\{

Allocate the user ci who has the largest response ratio to legal operating vehicle ti that ranked in the first row of the vehicles' queue;

Delete the legal operating vehicle ti form the scheduling queue of the vehicles.

5) Repeat step 4) until the legal operating vehicles' queue is empty.

\section{Experimental Analyses}

In order to verify the algorithm that the paper designed can get the higher scheduling rate, the better system throughput, efficiently solve the problem of the insufficient legal operating vehicles and the problem of hard to take a taxi, the paper simulates with the part of main streets of the Yu Yang district of Yulin city. Assume there are a small system with 200 users that calling taxi service in the area and 40 legal operating vehicles. Assume that the probability of finding the legal operating vehicles is $\mathrm{p} \%$, the value of $p$ is decided by three factors-the number of the legal operating vehicles, the way to find the legal operating vehicles and the number of the illegal operating vehicles ${ }^{[6]}$. More legal operating vehicles, more ways to search the legal operating vehicles, less illegal operating vehicles will cause the bigger $p$. In order to analyze better, this paper assume that the number of the illegal operating vehicles and the number of the legal operating vehicles are fixed. Compare the designed scheduling algorithm with the random drive of the taxi drivers, the result shown in Figure 6. 


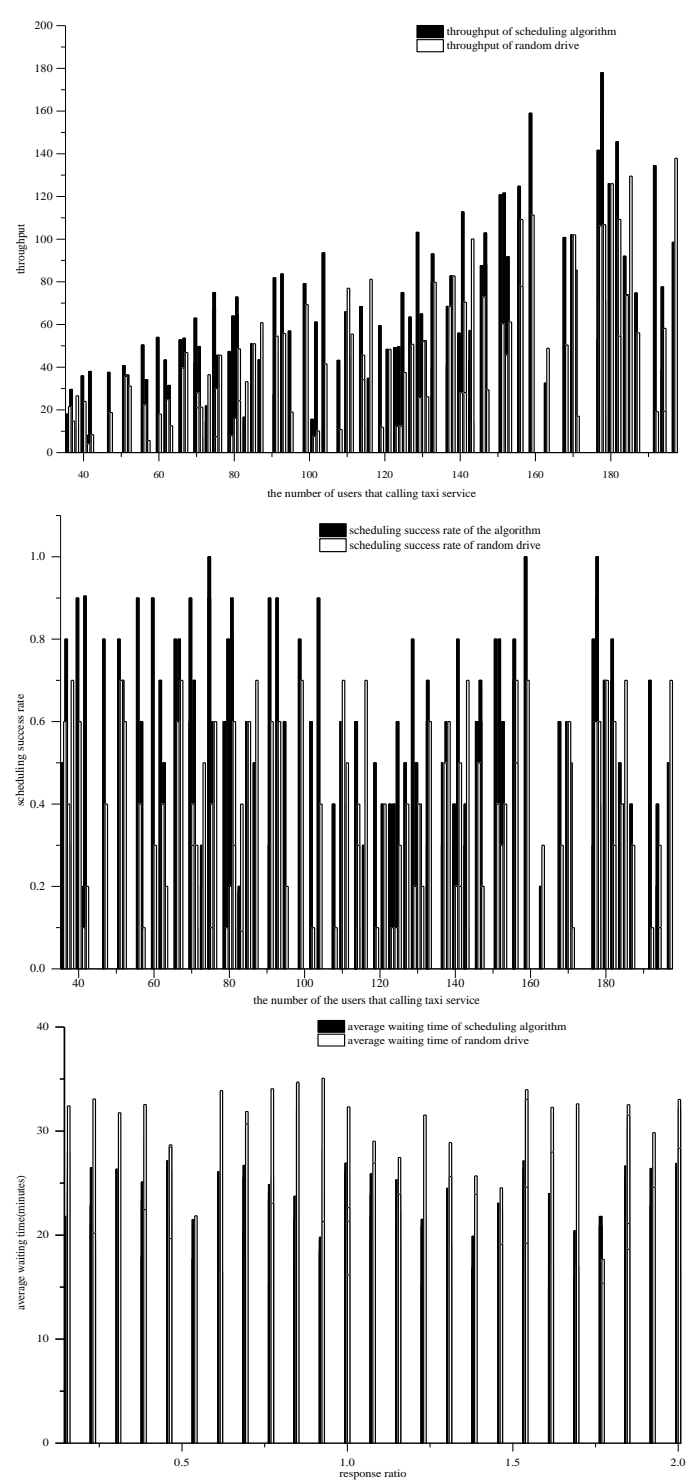

Figure 6. Scheduling Performance Comparison Diagram

The success rate, the throughput, the average waiting time of the algorithm designed in this paper is all superior to the case of random driver. We can figure out from $\mathrm{F}$ igure 6 that the algorithm can get better effect.

\section{Conclusions}

The system designed in this paper efficiently solved the problem of insufficient quantity of legal operating vehicles. Through the simulation experiment, we can figure out that the scheduling system can distinctly improve the success rate, the throughput of the legal operating vehicles and decrease the average waiting time of the users. It can efficiently help the passengers to solve the difficulty that they cannot find the legal operating vehicles when they need. The system can restrain the overflow of the illegal operating vehicles from a certain extent.

\section{Acknowledgments}

Here, I would like to show my deepest gratitude to the support of the Production-study-research Cooperation Projects of Yulin technology division. 


\section{References}

[1] ZHOU X C. SHI L F. ZHOU J, “A design of taxi dispatch center system”, Journal of Application of Electronic Technique, vol. 23, no. 9, (2010), pp. 94-97.

[2] Yue M C,De Y, "Real-Time Traffic Management under Emergency Evacuation Based on Dynamic Traffic Assignment", IEEE ICAL 2008 Conference, vol. 17, no. 4, (2008), pp. 225-230.

[3] Quddus M A, Noland R B, Ochieng W Y, "A high accuracy fuzzy logic based map matching algorithm for road transport", Journal of Intelligent Transportation Systems, vol. 10, no. 3, (2006), pp. 103-115.

[4] Qi W W, "Supervision and Countermeasure Research of Illegal Operating Vehicles-Taxi Market in Shanghai as an Example", Shanghai: East China University of Science and Technology,(2012).

[5] Hao Wang, Der Horng Lee, Ruey Cheu, "PDPTW based taxi dispatch modeling for booking service", Fifth International Conference on Natural Computation, (2009) October 13-11.

[6] J. Kimura, "Pology and vehicular motion constraints", Proceedings of 11th International IEEE Conference on Intelligent Transportation Systems, (2008) September 25-9. 
International Journal of Grid and Distributed Computing Vol. 9, No. 11 (2016) 